\title{
A Facile Method for Preparing UiO-66 Encapsulated Ru Catalyst and its Application in Plasma-Assisted $\mathrm{CO}_{2}$ Methanation
}

\author{
Weiwei Xu, Mengyue Dong, Lanbo Di *D and Xiuling Zhang * \\ College of Physical Science and Technology, Dalian University, Dalian 116622, China; \\ xuweiwei0626@sina.com (W.X.); dmy_up@sina.com (M.D.) \\ * Correspondence: dilanbo@dlu.edu.cn (L.D.); zhangxiuling@dlu.edu.cn (X.Z.); \\ Tel.: +86-411-8740-2712 (L.D. \& X.Z.)
}

Received: 12 September 2019; Accepted: 4 October 2019; Published: 10 October 2019

\begin{abstract}
With increasing applications of metal-organic frameworks (MOFs) in the field of gas separation and catalysis, the preparation and performance research of encapsulating metal nanoparticles (NPs) into MOFs (M@MOF) have attracted extensive attention recently. Herein, an Ru@UiO-66 catalyst is prepared by a one-step method. Ru NPs are encapsulated in situ in the UiO-66 skeleton structure during the synthesis of UiO-66 metal-organic framework via a solvothermal method, and its catalytic activity for $\mathrm{CO}_{2}$ methanation with the synergy of cold plasma is studied. The crystallinity and structural integrity of UiO-66 is maintained after encapsulating Ru NPs according to the X-ray diffraction (XRD), Fourier transform infrared spectroscopy (FTIR), and scanning electron microscopy (SEM). As illustrated by X-ray photoelectron spectroscopy (XPS), high resolution transmission electron microscopy (HRTEM), and mapping analysis, the Ru species of the hydration ruthenium trichloride precursor are reduced to metallic Ru NPs without additional reducing processes during the synthesis of Ru@UiO-66, and the Ru NPs are uniformly distributed inside the Ru@UiO-66. Thermogravimetric analysis (TGA) and $\mathrm{N}_{2}$ sorption analysis show that the specific surface area and thermal stability of Ru@UiO-66 decrease slightly compared with that of UiO-66 and was ascribed to the encapsulation of Ru NPs in the UiO-66 skeleton. The results of plasma-assisted catalytic $\mathrm{CO}_{2}$ methanation indicate that $\mathrm{Ru} @ \mathrm{UiO}-66$ exhibits excellent catalytic activity. $\mathrm{CO}_{2}$ conversion and $\mathrm{CH}_{4}$ selectivity over $\mathrm{Ru} @$ UiO-66 reached $72.2 \%$ and $95.4 \%$ under $13.0 \mathrm{~W}$ of discharge power and a $30 \mathrm{~mL} \cdot \mathrm{min}^{-1}$ gas flow rate $\left(V_{\mathrm{H}_{2}}: V_{\mathrm{CO}_{2}}=4: 1\right)$, respectively. Both values are significantly higher than pure UiO-66 with plasma and $\mathrm{Ru} / \mathrm{Al}_{2} \mathrm{O}_{3}$ with plasma. The enhanced performance of $\mathrm{Ru} @ \mathrm{UiO}-66$ is attributed to its unique framework structure and excellent dispersion of Ru NPs.
\end{abstract}

Keywords: metal-organic frameworks; Ru NPs; encapsulation; $\mathrm{CO}_{2}$ methanation; plasma

\section{Introduction}

Metal-organic frameworks (MOFs) are a series of porous crystal materials self-assembled by metal ions and organic ligands through coordination bonds [1-3]. The properties of specific surface area, porosity, and tunable functional structure make MOFs promising candidates in many applications such as gas storage and separation, drug delivery, chemical sensing, and catalysis [4-8]. As a typical Zr-based MOF, UiO-66 was first synthesized by Cavka et al. [9] and named after the University of Oslo. It has a perfect $\mathrm{Zr}_{6} \mathrm{O}_{4}(\mathrm{OH})_{4}$ octahedral framework structure and exhibits exceptional thermal stability. In addition, UiO-66 has been widely utilized in the separation and conversion of $\mathrm{CO}_{2}[6,10-13]$.

The utility of UiO-66 as a support for metal catalysts (M/UiO-66, $\mathrm{M}=\mathrm{Cu}, \mathrm{Au}, \mathrm{Pd}, \mathrm{Pt}, \mathrm{Ru}$, etc.) has been extensively studied by researchers recently [14-19]. For example, Milet et al. [18] reported 
$\mathrm{Pt} / \mathrm{UiO}-66$ catalysts prepared by the double solvent method: impregnation of the UiO-66 support with the aqueous solution of $\mathrm{H}_{2} \mathrm{PtCl}_{6}$, and then reduction with $\mathrm{NaBH}_{4}$ solution. The $\mathrm{Pt} / \mathrm{UiO}-66$ exhibited excellent performance for $\mathrm{CO}_{2}$ methanation. The $\mathrm{CO}_{2}$ conversion and $\mathrm{CH}_{4}$ selectivity were as high as $50 \%$ and $36 \%$ at $350{ }^{\circ} \mathrm{C}$ with a $\mathrm{CO}_{2}: \mathrm{H}_{2}$ molar ratio of $1: 5.2$ and $1650 \mathrm{~h}^{-1}$ gas hourly space velocity (GHSV), respectively. Compared with the simple impregnation method, encapsulating metal nanoparticles (MNPs) into the skeleton structure of the MOF template can adjust the size distribution of MNPs and prepare high-performance MNPs@MOF catalysts [20]. Li et al. [21] synthesized UiO-66-encapsulated nano-palladium catalysts (Pd@UiO-66). As described, the $\mathrm{Pd}(\mathrm{acac})_{2}$ was first prepared, and then $1 \mathrm{~g}$ of UiO-66 and Pd(acac) 2 solutions were mixed to synthesize Pd@UiO-66. Small Pd NPs (2.2 nm) were obtained due to the confinement of the small pore structure of UiO-66. The synthesized Pd@UiO-66 exhibited high catalytic activity and stability for continuous catalytic upgrading of ethanol to n-butanol. The ethanol conversion and the n-butanol selectivity over the best Pd@UiO-66 catalyst was 49.9\% and $50.1 \%$, respectively, during a $200-\mathrm{h}$ evaluation. The high performance was attributed to the close synergy of highly distributed Pd NPs and coordinatively unsaturated Zr sites in UiO-66. Dong et al. [22] encapsulated Pd NPs in UiO-66 with a microwave-assisted method. The pores of UiO-66 were activated, and the metal precursors were reduced at the same time in the presence of $\mathrm{NaBH}_{4}$. The obtained Pd@UiO-66 exhibited high catalytic activity for Suzuki-Miyaura coupling reactions at mild conditions. Therefore, using MOFs with tunable porous structures as supports, growth of the metal NPs could be confined due to the encapsulation [23]. Consequently, high-performance MOFs supported metal catalysts with small size and high dispersion metal NPs can be generally obtained [24-26]. However, to synthesize the above MOFs-supported metal catalysts, there are two or more steps required, the synthesis of the MOF support and the impregnation, and the reduction of the supported/encapsulated metal precursors in the presence of reducing agents [18]. Therefore, this process is generally sophisticated and time-consuming.

The $\mathrm{CO}_{2}$ methanation has great prospects in economic and environmental applications since most of the fuel resources and one-carbon molecules (C1) can be regenerated from $\mathrm{CO}_{2}[27,28]$. The emerging plasma-assisted activation of $\mathrm{CO}_{2}$ for methanation can provide the high energy for $\mathrm{CO}_{2}$ decomposition and overcome the relatively harsh conditions and reaction devices required for conventional thermochemical conversion [29-33]. Ru-based catalysts, due to their efficient activity, have been applied in $\mathrm{CO}_{2}$ methanation extensively. This is because, in the process of $\mathrm{CO}_{2}$ hydrogenation, the active $\mathrm{Ru}$ sites are more selective to the formation of methane, which can promote the reaction of $\mathrm{CO}_{2}$ along the methanation path in the hydrogen-rich environment [34-37].

In this work, we report a simple and efficient method for synthesizing Ru@UiO-66 via in situ encapsulation of $\mathrm{Ru} \mathrm{NPs}$ by the reduction of the $\mathrm{RuCl}_{3}$ precursor during the growth of UiO-66 framework structure. The crystallinity and structural integrity of Ru@UiO-66 are similar to UiO-66. The synthesized Ru@UiO-66 exhibits high performance for plasma-assisted catalytic $\mathrm{CO}_{2}$ methanation.

\section{Experimental}

\subsection{Materials}

Zirconium tetrachloride $\left(\mathrm{ZrCl}_{4}, 98 \%\right)$, terephthalic acid (BDC, 99\%) and hydrochloric acid ( $\mathrm{HCl}, 37 \%)$ were supplied by Sinopharm Chemical Reagent Co., Ltd. (Shanghai, China). $N, N$-dimethylformamide (DMF, 99\%) and hydration ruthenium trichloride $\left(\mathrm{RuCl}_{3} \cdot \mathrm{xH}_{2} \mathrm{O}, \mathrm{Ru}\right.$ content 37\%) were purchased from Tianjin Zhiyuan Co., Ltd. (Tianjin, China) and Walixi Chemical Co., Ltd. (Guangdong, China), respectively. Anhydrous methanol $\left(\mathrm{CH}_{3} \mathrm{OH}, 99.5 \%\right)$ was bought from Tianjin Kermel Co., Ltd. (Tianjin, China). All chemicals were used without further purification. High purity $\mathrm{H}_{2}(>99.999 \%)$ was generated by an $\mathrm{HGH}-500 \mathrm{E}$ hydrogen generator, and high purity $\mathrm{CO}_{2}$ and $\mathrm{Ar}$ (>99.999\%) were obtained from the Guangming Research \& Design Institute of Chemical Industry Co., Ltd. (Dalian, China). 


\subsection{Synthesis of UiO-66 and Ru@UiO-66}

The strategy for preparing UiO-66 and Ru@UiO-66 is depicted in Figure 1. UiO-66 was prepared by a solvent thermal method previously reported in [38]. In brief, $1.165 \mathrm{~g}$ of $\mathrm{ZrCl}_{4}$ and $0.831 \mathrm{~g}$ of BDC were dissolved in $30 \mathrm{~mL} \mathrm{DMF}$, and then $0.8 \mathrm{~mL}$ of concentrated $\mathrm{HCl}(37 \%)$ was added. The obtained mixture was placed in an ultrasonic reactor for $20 \mathrm{~min}$ and heated at $120^{\circ} \mathrm{C}$ for $24 \mathrm{~h}$ in a Teflon-lined steel autoclave. After cooling to room temperature, the obtained suspension of UiO-66 was centrifuged by a centrifuge machine ( $9000 \mathrm{rpm}, 10 \mathrm{~min}$ ), and rinsed with $25 \mathrm{~mL}$ of DMF and $25 \mathrm{~mL}$ of anhydrous methanol three times, respectively. The obtained UiO- 66 was dried at $100{ }^{\circ} \mathrm{C}$ under vacuum. The synthesis procedure of Ru@UiO-66 was similar to that of UiO-66. The difference was that $0.415 \mathrm{~g}$ of $\mathrm{RuCl}_{3}$ with $1.165 \mathrm{~g}$ of $\mathrm{ZrCl}_{4}$ and $0.831 \mathrm{~g}$ of BDC were added into $30 \mathrm{~mL}$ of DMF. The other parameters were the same as that for synthesizing the pure UiO-66. The mass fraction of $\mathrm{Ru}$ determined by inductively coupled plasma optical emission spectrometer (ICP-OES) in Ru@UiO-66 was $2.83 \mathrm{wt} \%$.

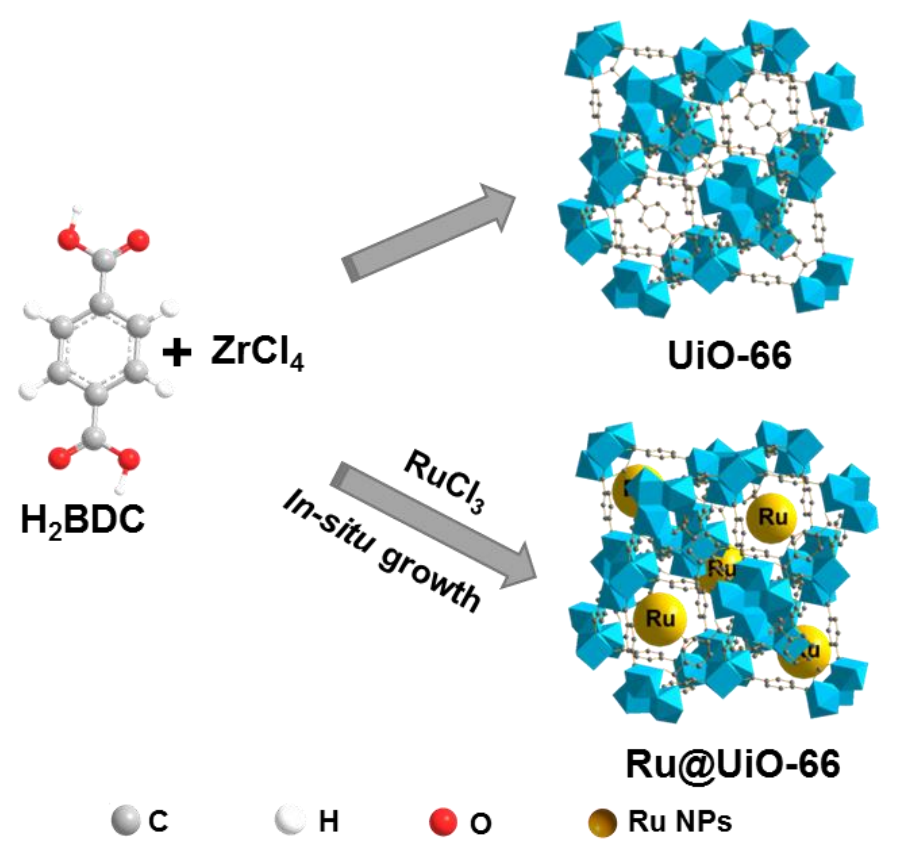

Figure 1. Schematic illustration for the synthesis of UiO-66 and Ru@UiO-66.

\subsection{Catalytic Evaluation}

The catalytic activity of the UiO-66 supported Ru catalysts was evaluated via a dielectric barrier discharge (DBD) plasma-assisted catalytic $\mathrm{CO}_{2}$ methanation reaction. The DBD plasma reactor is composed of a coaxial quartz tube (inner diameter: $8 \mathrm{~mm}$, outer diameter: $10 \mathrm{~mm}$ ), copper rod inner electrode (diameter: $2 \mathrm{~mm}$ ) and $1 \mathrm{~mm}$ of a copper coil ground electrode. The discharge length and discharge gap are $25 \mathrm{~mm}$ and $2.5 \mathrm{~mm}$, respectively. Typically, $0.3 \mathrm{~g}$ of samples were placed in the discharge area at a sinusoidal peak-to-peak voltage of $19.2 \mathrm{kV}$. The working gases of $\mathrm{CO}_{2}$ and $\mathrm{H}_{2}$ were mixed into the reactor after being measured by the mass flow meter (total flow rate was $30 \mathrm{~mL} \cdot \mathrm{min}^{-1}, V_{\mathrm{H} 2}: V_{\mathrm{CO} 2}=4: 1$ ), while the outlet gas flow rate was measured by a soap film bubble flow meter. The gaseous products were analyzed online by a gas chromatograph (Tianmei GC-7890, Shanghai, China) equipped with a thermal conductivity detector (TCD). A type of FLUKE MT4 Max+ IR thermometer was used to monitor the temperature during the discharge process. The temperature of the reaction was ca. $200{ }^{\circ} \mathrm{C}$. To evaluate the performance of $\mathrm{CO}_{2}$ methanation under cold plasma-assistance, $\mathrm{CO}_{2}$ conversion $\left(\mathrm{X}_{\mathrm{CO} 2}\right)$, selectivity $(S)$, and yield $(Y)$ of the products were calculated as the reference [39]: 


$$
\begin{aligned}
X_{\mathrm{CO}_{2}} & =\frac{F_{\mathrm{CO}_{2}}-F_{\mathrm{CO}_{2}}^{\prime}}{F_{\mathrm{CO}_{2}}} \times 100 \% \\
S_{\mathrm{CO}} & =\frac{F_{\mathrm{CO}}^{\prime}}{F_{\mathrm{CO}_{2}}-F_{\mathrm{CO}_{2}}^{\prime}} \times 100 \% \\
S_{\mathrm{CH}_{4}} & =\frac{F_{\mathrm{CH}_{4}}^{\prime}}{F_{\mathrm{CO}_{2}}-F_{\mathrm{CO}_{2}}^{\prime}} \times 100 \% \\
Y & =X \times S \times 100 \%
\end{aligned}
$$

where $F$ and $F^{\prime}$ are the inlet and outlet gas flow rates, respectively.

\subsection{Catalysts Characterization}

The X-ray diffraction (XRD) patterns were completed using a DX-2700 (Dandong, China) diffractometer with $\mathrm{Cu} \mathrm{K} \alpha$ radiation $(\lambda=1.54178 \AA)$ at $40 \mathrm{kV}$ and $30 \mathrm{~mA}$, and the step size of the measurement was $0.03^{\circ}$. Fourier transform infrared (FTIR) spectra were recorded in the range of $400-4000 \mathrm{~cm}^{-1}$ on a Nicolet AVATAR 370 (Waltham, MA, USA) infrared spectrometer. A Zeiss Sigma 500 (Jena, Germany) scanning electron microscope (SEM), operating at $10 \mathrm{kV}$, was utilized to characterize the morphology of the sample crystals. The X-ray photoelectron spectroscopy (XPS) spectra were recorded on a Thermo ESCALAN 250 spectrometer (Waltham, MA, USA) with Al K $\alpha$ $(1486.6 \mathrm{eV})$. The high-resolution transmission electron microscopy (HRTEM) and mapping were measured on a Tecnai G2 f20 s-twin (Hillsboro, OR, USA) transmission electron microscope. Binding energies were calibrated using $\mathrm{C} 1 \mathrm{~s}(284.6 \mathrm{eV})$ as the standard. The spectra were deconvoluted by the XPSPEAK41 program. $\mathrm{N}_{2}$ adsorption-desorption isotherms of the samples were performed on a NOVA 2200e analyzer (Boynton Beach, FL, USA) at a temperature of $77 \mathrm{~K}$. The thermal stability of the samples was recorded by a Mettler TGA/DSC3+ thermal analyzer (Schwerzenbach, Switzerland) with a heating rate of $5^{\circ} \mathrm{C} \cdot \mathrm{min}^{-1}$. Inductively coupled plasma optical emission spectrometer (ICP-OES) determination was executed on an Agilent 700 (Santa Clara, CA, USA) instrument.

\section{Results and Discussion}

Figure 2 illustrates the XRD patterns of Ru@UiO-66 and UiO-66. Obviously, the main diffraction peaks of Ru@UiO-66 at $2 \theta=7.3^{\circ}, 8.5^{\circ}$ and $25.7^{\circ}$ match well with UiO-66, revealing that no significant loss is observed in UiO-66 crystallinity after the introduction of $\mathrm{RuCl}_{3}$ in the synthesis of UiO-66. No diffraction peaks corresponding to Ru species can be detected in Ru@UiO-66, which may be ascribed to the low loading amount of Ru species, and/or the encapsulation of the Ru species into the UiO-66 skeleton structure.

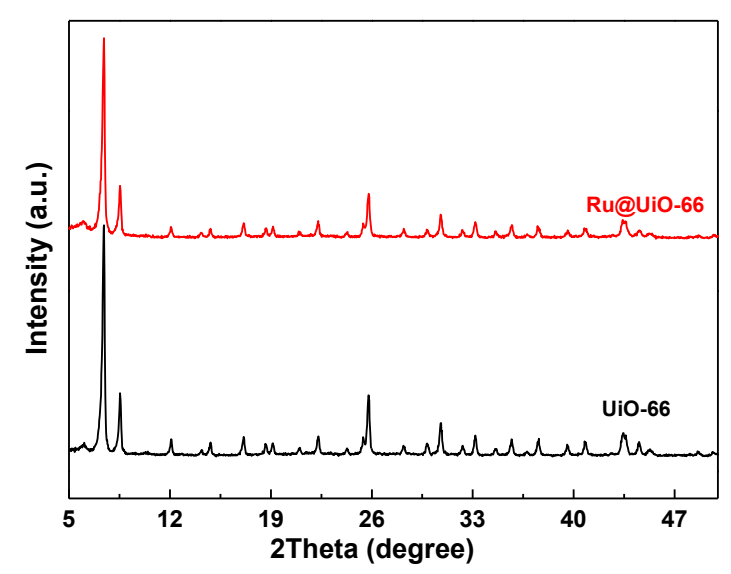

Figure 2. X-ray diffraction (XRD patterns of Ru@UiO-66 and UiO-66. 
FTIR spectra of Ru@UiO-66 and UiO-66 were measured, as illustrated in Figure 3. The FTIR spectra of Ru@UiO-66 and UiO-66 display the same peaks in the region of 4000 to $400 \mathrm{~cm}^{-1}$. The broad absorption band in the region of 3700 to $3200 \mathrm{~cm}^{-1}$ corresponding to the stretching vibration of O-H, to a large extent, is attributed to the residual solvent and adsorbed water [1,40]. In addition, it can also be induced by the $\mathrm{OH}$ from deprotonation of the carboxylate groups. The bands centered at ca. $1700 \mathrm{~cm}^{-1}$ and $1400 \mathrm{~cm}^{-1}$ correspond to the symmetrical stretching vibrations of the $\mathrm{C}=\mathrm{O}$ bond in the -COOgroup in the framework. The bands at $1506 \mathrm{~cm}^{-1}$ and $1581 \mathrm{~cm}^{-1}$ are assigned to the $\mathrm{C}=\mathrm{C}$ stretching vibration of the phenyl ring. These indicate that the main functional groups in the BDC organic linker have been kept for Ru@UiO-66 and UiO-66. Furthermore, the peak at $745 \mathrm{~cm}^{-1}$ is consistent with the symmetric vibration peak of $\mathrm{O}-\mathrm{Zr}-\mathrm{O}$ and the symmetric vibration peak of $\mathrm{O}-\mathrm{Zr}-\mathrm{O}$ at $663 \mathrm{~cm}^{-1}[7,10]$. All spectra have weak absorption bands in the region of $600-400 \mathrm{~cm}^{-1}$ pertaining to the in-plane and out-of-plane bending vibrations of -COO-. It was proven that $\mathrm{Zr}$, as the coordination center in the organic framework, is formed by bridging with the organic ligand terephthalic acid through the bond of $\mu_{3}-\mathrm{O}$ [41]. However, the vibration peaks related to ruthenium cannot be detected from the FTIR spectra, suggesting that the ruthenium does not exist as a combined state in the UiO-66 skeleton.

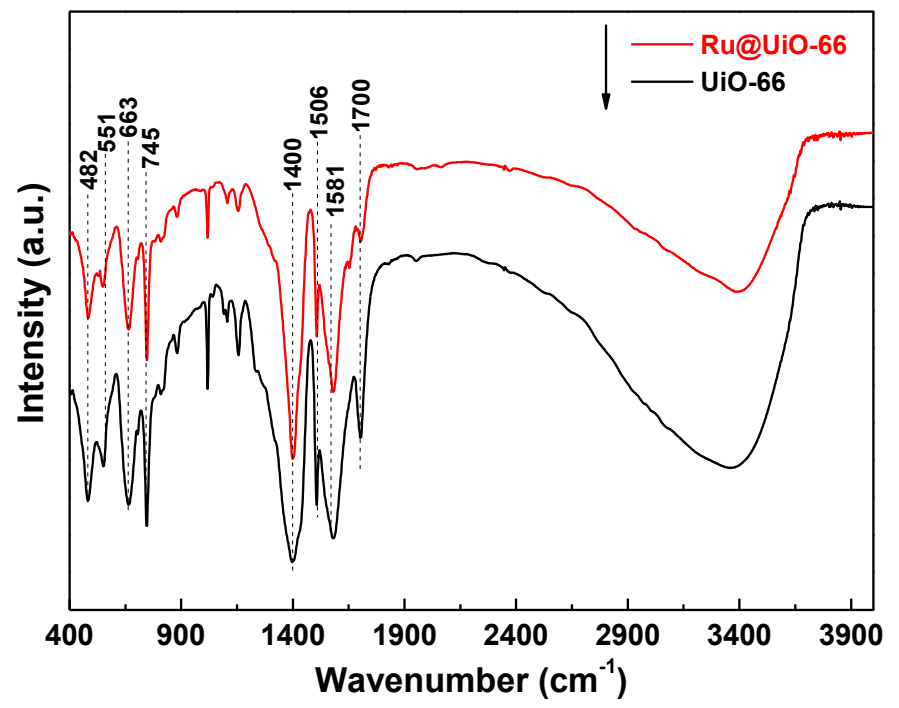

Figure 3. Fourier transform infrared spectroscopy (FTIR) spectra of Ru@UiO-66 and UiO-66.

The typical SEM images of Ru@UiO-66 and UiO-66 are shown in Figure 4. Ru@UiO-66 exhibits a similar morphology with UiO-66 in spite of the introduction of ruthenium in its skeleton. Furthermore, there are no obvious differences in the grain sizes of $\mathrm{Ru} @ \mathrm{UiO}-66$ and UiO-66 according to the SEM images. The average grain size distribution for Ru@UiO-66 $(202 \pm 29 \mathrm{~nm})$ is close to UiO-66 $(201 \pm 22 \mathrm{~nm})$. Both values demonstrate that in situ addition of the Ru precursor during the fabrication of UiO-66 has no effect on the formation and uniform growth of the grains of Ru@UiO-66.

The XPS spectra of survey, Ru3p, Zr3d, and Cl2p over Ru@UiO-66 are shown in Figure 5. The elements of carbon, oxygen zirconium, and ruthenium are observed clearly in Figure 5a. Among these elements, carbon, oxygen, and zirconium constitute the catalysts. It is noted in Figure $5 \mathrm{~b}$ that the peak appearing at $462.4 \mathrm{eV}$ is attributed to $3 \mathrm{p}_{3 / 2}$ of $\mathrm{Ru}^{0}$ [36]. This reveals that the $\mathrm{Ru}^{3+}$ ions from $\mathrm{RuCl}_{3}$ have been reduced into metallic $\mathrm{Ru}^{0}$ directly, without extra reduction processes. During the synthesis of Ru@UiO-66, BDC and DMF serve as the skeleton of UiO-66 and solvent, respectively, and both of them

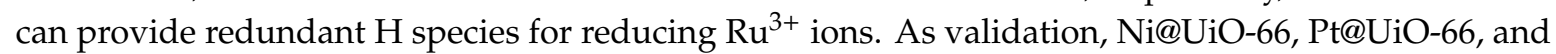
Pd@UiO-66 have been successfully synthesized by the same method. The peak at $475 \mathrm{eV}$ might be the Auger electron of O KL1L1 and KL1L23, which does not belong to any Ru species [42]. As mentioned in Figure 4, the peaks related to ruthenium are not detected in the FTIR spectrum of Ru@UiO-66, which further suggests that ruthenium existed in the framework of Ru@UiO-66 as a metallic state. 
The $\mathrm{Zr}_{3} \mathrm{~d}_{5 / 2}$ and $\mathrm{Zr} 3 \mathrm{~d}_{3 / 2}$ in $\mathrm{Ru} @ U \mathrm{UiO}-66$ at $182.7 \mathrm{eV}$ and $185.1 \mathrm{eV}$ are attributed to the $\mathrm{Zr}^{4+}$ in O-Zr-O [7], which is also confirmed by the FTIR result (Figure 3). As shown in Figure 5c, no $\mathrm{Cl}$ can be detected, suggesting that the $\mathrm{Cl}^{-}$ions have been removed by washing during preparation of $\mathrm{Ru} @ \mathrm{UiO}-66$.
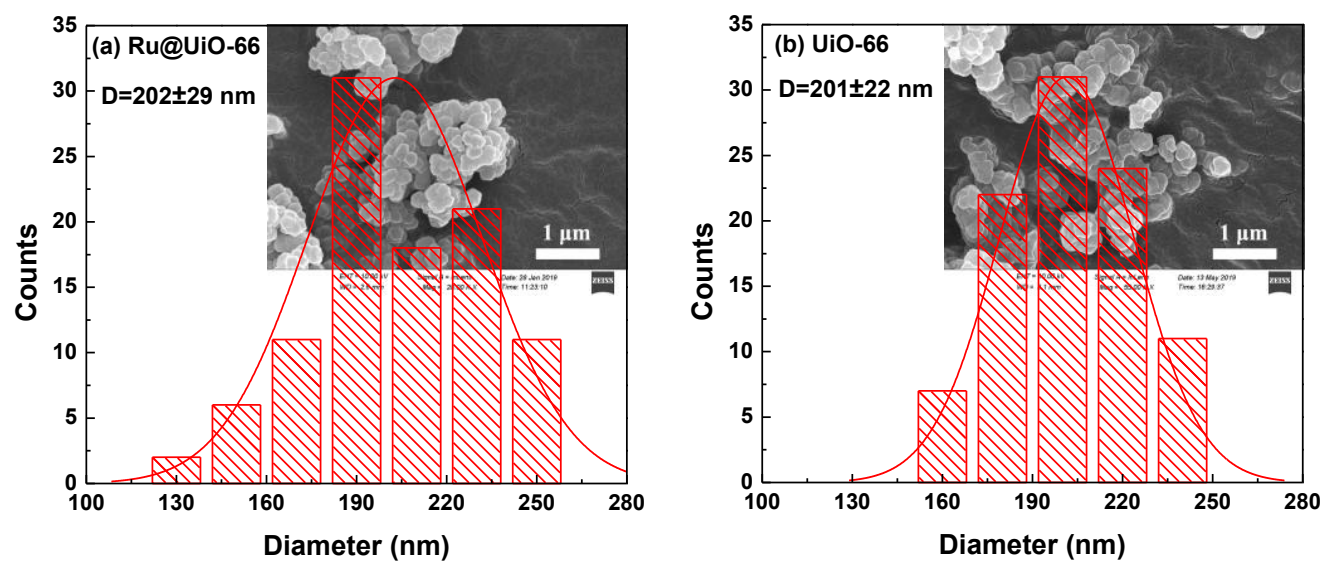

Figure 4. Scanning electron microscopy (SEM) images and the corresponding histograms of the size distribution of (a) Ru@UiO-66 and (b) UiO-66.
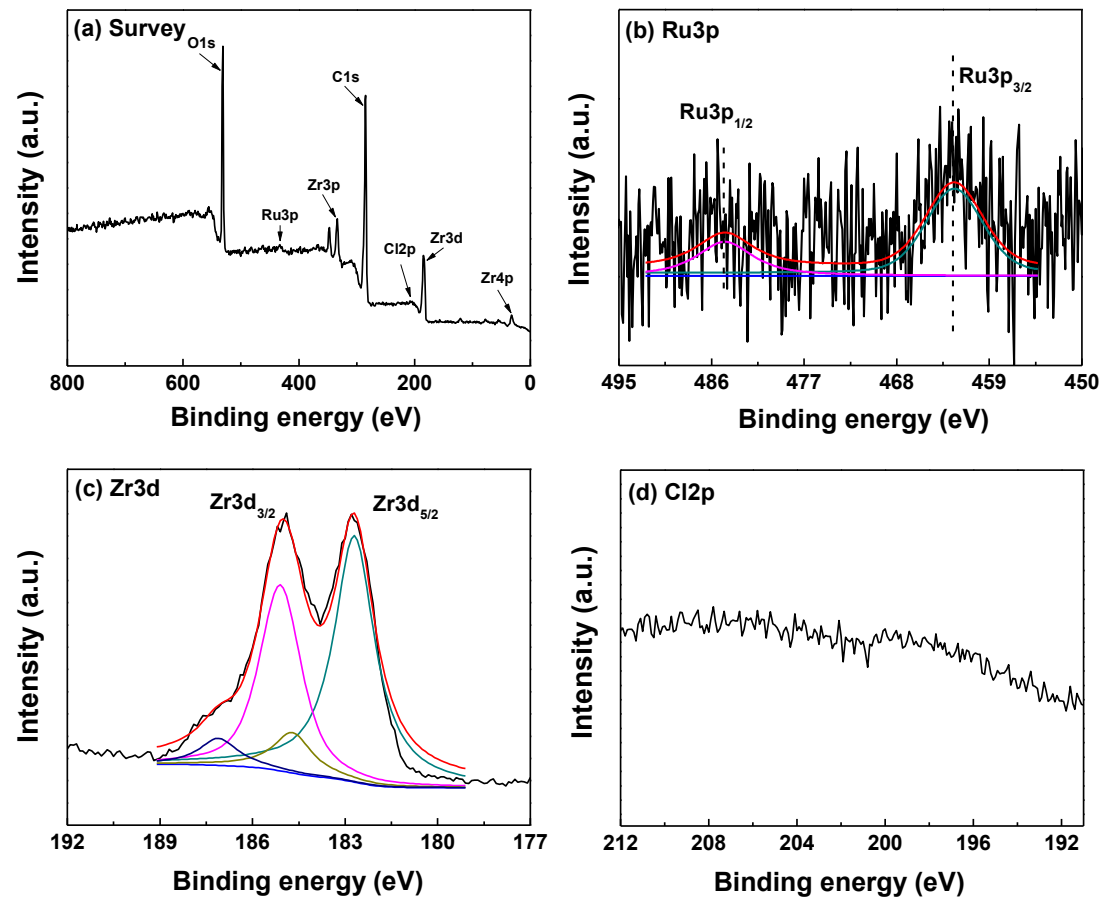

Figure 5. The X-ray photoelectron spectroscopy XPS spectra of (a) survey, (b) Ru3p, (c) Zr3d, and (d) Cl2p over Ru@UiO-66 and UiO-66.

The HRTEM and mapping measurements were further completed to observe the structure of $\mathrm{Ru} @ U \mathrm{UiO}-66$ as presented in Figure 6. Figure 6a,b clearly display that Ru NPs are regularly encapsulated in the framework of UiO-66 and $\{101\}$ lattice fringes with an interplanar spacing of $0.204 \mathrm{~nm}$ [43]. This is in accordance with the low content of $\mathrm{Ru}^{0}$ on surface XPS spectra in Figure 5. The Ru NPs size distribution is presented in Figure 6c, it shows that Ru NPs have a small particle diameter of $1.66 \mathrm{~nm}$ and central distribution in the framework of UiO-66. Mapping analysis in random areas in Figure $6 \mathrm{~d}-\mathrm{h}$ reveals that $\mathrm{C}, \mathrm{O}$, and $\mathrm{Zr}$ elements abundantly exist in Ru@UiO-66, which are the main components of UiO-66 skeleton. In addition, Ru elements are evenly distributed in Ru@UiO-66. 

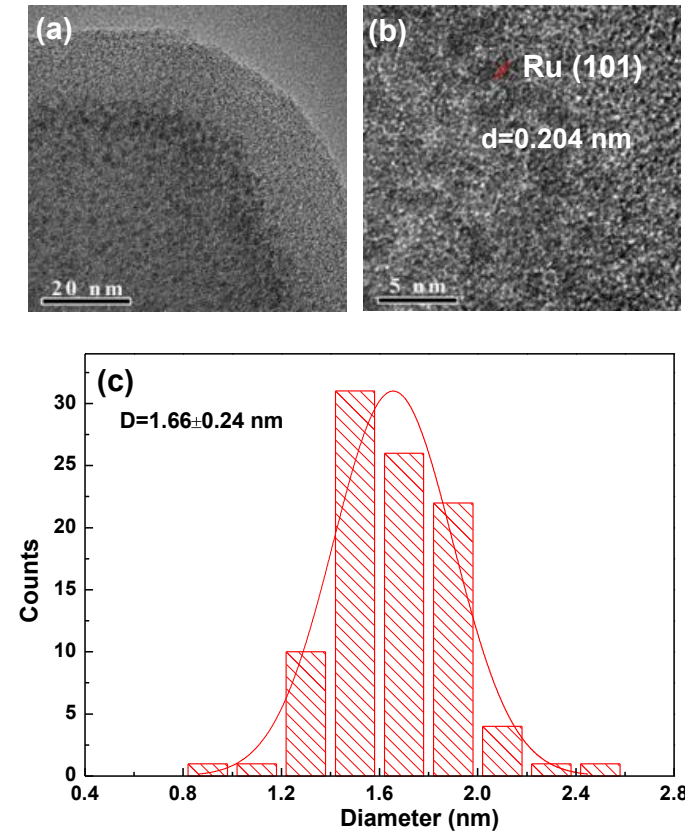
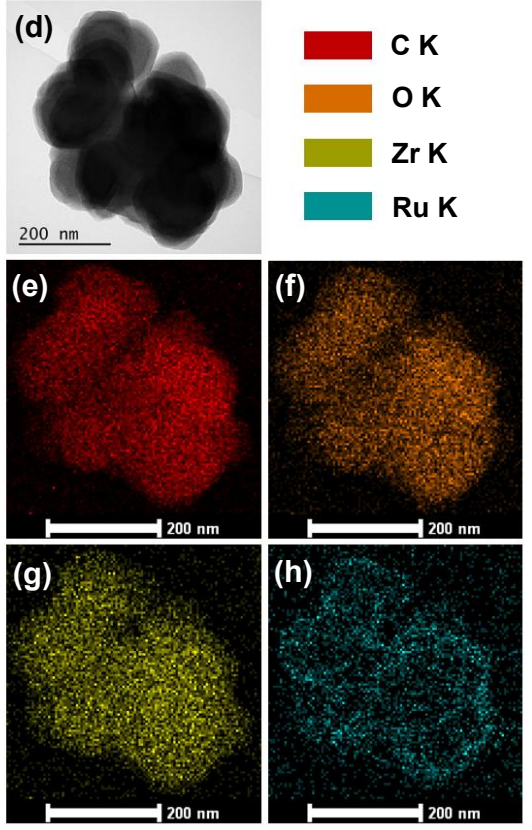

Figure 6. (a,b) The HRTEM images of Ru@UiO-66. (c) The size distribution histogram of Ru NPs. (d-h) The mapping of C, O, Zr, Ru elements on Ru@UiO-66 catalyst.

Figure 7 gives the nitrogen adsorption-desorption isotherms and the classical Barrett-Joyner-Halenda (BJH) pore size distribution curves of Ru@UiO-66 and UiO-66. The specific surface area of Ru@UiO-66 is $766.4 \mathrm{~m}^{2} \cdot \mathrm{g}^{-1}$, as calculated by the Brunauer-Emmett-Teller (BET) method, which is slightly lower than that of UiO-66 $\left(996.9 \mathrm{~m}^{2} \cdot \mathrm{g}^{-1}\right)$. The pore diameter of Ru@UiO-66 $(3.4 \mathrm{~nm})$ is equal to UiO-66. This indicates that the addition of the precursor $\mathrm{RuCl}_{3}$ in the synthesis of Ru@UiO-66 did not affect the growth of the UiO-66 skeleton structure, and the pore size and pore volume of Ru@UiO-66 are similar to that of UiO-66.
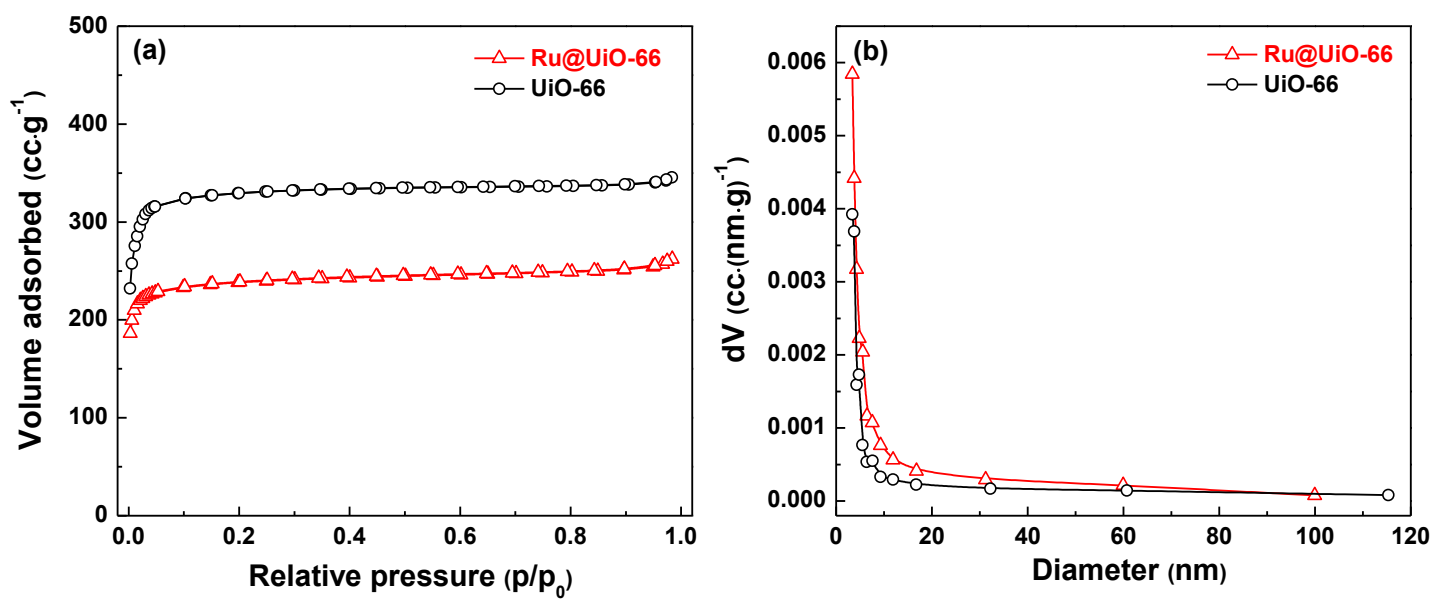

Figure 7. (a) Nitrogen adsorption-desorption isotherms and (b) the BJH pore size distribution curves of Ru@UiO-66 and UiO-66.

To evaluate the thermal stability of Ru@UiO-66 and UiO-66, thermo-gravimetric analysis (TGA) was carried out in air, as shown in Figure 8. The weight loss of the three samples under $100{ }^{\circ} \mathrm{C}$ is attributed to desorption of water and residual solvent adsorbed at the surface. The TGA curve of UiO-66 declines rapidly at about $450{ }^{\circ} \mathrm{C}$, suggesting the decomposition of the organic linker in the framework $[8,44,45]$. In contrast, the decomposition temperature of Ru@UiO-66 (ca. $350{ }^{\circ} \mathrm{C}$ ) is lower than that of UiO-66 $\left(450^{\circ} \mathrm{C}\right)$, which may result from the presence of the Ru species. In other words, 
the interaction between $-\mathrm{COO}^{-}$and $\mathrm{Zr}^{4+}$ is weakened due to the existence of the $\mathrm{Ru}$ species, and the $\mathrm{Ru}$ species facilitate the thermal decomposition of the framework at high temperature.

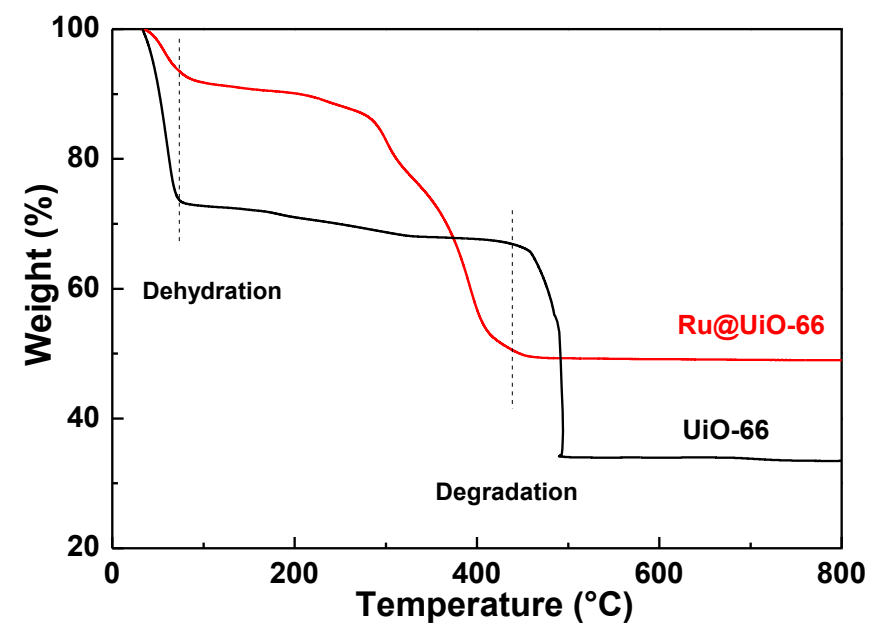

Figure 8. Thermogravimetric analysis (TGA) curves of Ru@UiO-66 and UiO-66.

The activity of $\mathrm{Ru} @ \mathrm{UiO}-66$ and $\mathrm{UiO}-66$ for plasma-assisted catalytic $\mathrm{CO}_{2}$ methanation were tested, as illustrated in Figure 9. For comparison, the activity data of $\mathrm{Ru} / \mathrm{UiO}-66$ (UiO-66 supported $\mathrm{Ru}$ prepared by incipient wetness impregnation method) taken from a previous work [38] was also illustrated in Figure 9. The loading amount of $\mathrm{Ru}$ in $\mathrm{Ru} @ \mathrm{UiO}-66$ and $\mathrm{Ru} / \mathrm{UiO}-66$ are close, and the reaction was performed under the same experimental parameters. The $\mathrm{CO}_{2}$ conversion of $\mathrm{Ru} @ \mathrm{UiO}-66$ is 3.6 times higher than $\mathrm{UiO}-66$, and the $\mathrm{CH}_{4}$ selectivity over $\mathrm{Ru} @ \mathrm{UiO}-66$ slightly increases and reaches 95.4\% at steady state. Even more interesting is that the products' selectivities of the two samples are quite different. The primary product of $\mathrm{Ru} @ \mathrm{UiO}-66$ is $\mathrm{CH}_{4}$, and the yield of $\mathrm{CH}_{4}$ reaches $68.9 \%$. While the product of $\mathrm{UiO}-66$ was mainly $\mathrm{CO}$, the yield of $\mathrm{CH}_{4}$ was less than $3 \%$. Due to the one-step preparation of $\mathrm{Ru} @ \mathrm{UiO}-66$, the ruthenium in the precursor $\mathrm{RuCl}_{3}$ is directly reduced to the metallic $\mathrm{Ru}$ and encapsulated in the skeletal structure of the UiO-66. Therefore, the Ru@UiO-66 catalyst with active $\mathrm{Ru}$ species exhibits a perfect performance for plasma-assisted catalytic $\mathrm{CO}_{2}$ methanation. In addition, the $\mathrm{CO}_{2}$ conversion over $\mathrm{Ru} / \mathrm{UiO}-66$ increased from $20.4 \%$ for pure $\mathrm{UiO}-66$ to $41.3 \%$. However, it is still much lower than that over the $\mathrm{Ru@UiO-66} \mathrm{catalyst} \mathrm{(72.2 \% ).} \mathrm{Moreover,} \mathrm{the} \mathrm{CH}_{4}$ selectivity over $\mathrm{Ru} / \mathrm{UiO}-66$ reaches $86.5 \%$, while it is only ca. 3\% for pure UiO-66. In summary, the $\mathrm{Ru} / \mathrm{UiO}-66$ possess much higher $\mathrm{CO}_{2}$ conversion activity, $\mathrm{CH}_{4}$ selectivity, and yield than pure UiO-66 due to the appearance of active $\mathrm{Ru}$ species. However, they exhibit poorer performance than the Ru@UiO-66 catalyst, which was mainly attributed to the encapsulation of highly dispersed active Ru species in the UiO-66 skeleton. These indicate that not only the Ru species but also the preparation methods play important roles in plasma-assisted $\mathrm{CO}_{2}$ conversion reactions.

The synergy of cold plasma and active $\mathrm{Ru}$ species play a vital role in the catalytic activity of $\mathrm{CO}_{2}$ methanation. Lee et al. [34] reported that the conversion of $5.369 \mathrm{wt} \% \mathrm{Ru} / \mathrm{Al}_{2} \mathrm{O}_{3}$ reached $23.2 \%$ under the synergy of DBD plasma. This is beyond the conversion of pure plasma and catalysts. Although this is the first report about the co-activation and conversion of $\mathrm{CO}_{2}$ by Ru-based catalysts with plasma, the conversion of $\mathrm{CO}_{2}$ is unsatisfactory. As for $\mathrm{UiO}-66$, with a strong adsorption ability of $\mathrm{CO}_{2}$, it can serve as the carrier of the metal catalyst to effectively improve $\mathrm{CO}_{2}$ conversion. Unlike $\mathrm{Ru} / \mathrm{UiO}-66$, the active Ru NPs are distributed in the framework of Ru@UiO-66 uniformly to participate in the $\mathrm{CO}_{2}$ methanation effectively. The high catalytic activity of Ru@UiO-66 is due to the high dispersion of Ru NPs and the high $\mathrm{CO}_{2}$ adsorption ability of the UiO-66 skeleton. 


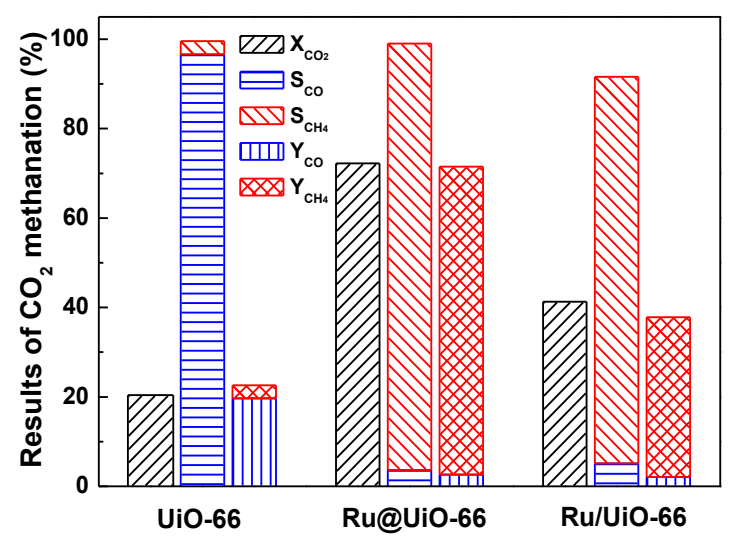

Figure 9. Dielectric barrier discharge (DBD) plasma-assisted $\mathrm{CO}_{2}$ conversion over UiO-66, Ru@UiO-66, and $\mathrm{Ru} / \mathrm{UiO}-66$, Reproduced from [38], Copyright Hefei Institutes of Physical Science, Chinese Academy of Sciences and IOP Publishing, 2019.

\section{Conclusions}

In summary, Ru@UiO-66 was successfully synthesized via a one-step solvothermal method. The $\mathrm{Ru}$ species from the $\mathrm{RuCl}_{3}$ precursor was reduced directly and embedded into the framework of UiO-66 during the synthesis of Ru@UiO-66, without an additional reducing process. The crystallinity and structural integrity of UiO-66 were maintained well after encapsulating Ru NPs, and the Ru NPs were uniformly distributed inside the framework of UiO-66. The results of the plasma-assisted $\mathrm{CO}_{2}$ methanation indicated that Ru@UiO-66 exhibited an unprecedented catalytic activity with the synergy of plasma. $\mathrm{CO}_{2}$ conversion and $\mathrm{CH}_{4}$ selectivity over $\mathrm{Ru} @ \mathrm{UiO}-66$ reached $72.2 \%$ and $95.4 \%$ under $13.0 \mathrm{~W}$ discharge power and $30 \mathrm{~mL} \cdot \mathrm{min}^{-1}$ gas flow rate $\left(V_{\mathrm{H}_{2}}: V_{\mathrm{CO}_{2}}=4: 1\right)$. The high performance of $\mathrm{Ru} @ \mathrm{UiO}-66$ can be ascribed to the synergy of the Ru NPs and cold plasma. The high $\mathrm{CO}_{2}$ adsorption ability of UiO-66 is essential for $\mathrm{CO}_{2}$ methanation. This work provides a simple method to synthesize high-performance MOF-supported Ru catalysts via a one-step solvothermal method to reduce and encapsulate the Ru NPs into the skeleton at the same time.

Author Contributions: Conceptualization, L.D. and X.Z.; Data curation, W.X. and M.D.; Investigation, W.X.; Project administration, L.D.; Supervision, L.D. and X.Z.; Writing—original draft, W.X.; Writing—review \& editing, X.Z.

Funding: This work is supported by National Natural Science Foundation of China (Nos. 21673026, 21773020, 11505019), the Liaoning Innovative Talents in University (No. LR2017025), the Liaoning Natural Science Foundation (No. 20180550085), and Graduate Education and Teaching Reform Fund of Dalian University.

Conflicts of Interest: The authors declare no conflict of interest.

\section{References}

1. Yang, F.; Li, W.; Tang, B. Facile synthesis of amorphous UiO-66 (Zr-MOF) for supercapacitor application. J. Alloy. Compd. 2018, 733, 8-14. [CrossRef]

2. Rungtaweevoranit, B.; Baek, J.; Araujo, J.R.; Archanjo, B.S.; Choi, K.M.; Yaghi, O.M.; Somotjai, G.A. Copper nanocrystals encapsulated in Zr-based metal-organic frameworks for highly selective $\mathrm{CO}_{2}$ hydrogenation to methanol. Nano Lett. 2016, 16, 7645-7649. [CrossRef] [PubMed]

3. Li, R.; Zhang, W.; Zhou, K. Metal-organic-framework-based catalysts for photoreduction of $\mathrm{CO}_{2}$. Adv. Mater. 2018, 30, 1705512. [CrossRef] [PubMed]

4. Li, B.; Wen, H.-M.; Zhou, W.; Chen, B. Porous metal-organic frameworks for gas storage and separation: What, How, and Why? J. Phys. Chem. Lett. 2014, 5, 3468-3479. [CrossRef] [PubMed]

5. Abid, H.R.; Ang, H.M.; Wang, S. Effects of ammonium hydroxide on the structure and gas adsorption of nanosized Zr-MOFs (UiO-66). Nanoscale 2012, 4, 3089-3094. [CrossRef] 
6. Wang, Y.; Hu, Z.; Kundu, T.; Cheng, Y.; Dong, J.; Qian, Y.; Zhai, L.; Zhao, D. Metal-organic frameworks with reduced hydrophilicity for postcombustion $\mathrm{CO}_{2}$ capture from wet flue gas. ACS Sustain. Chem. Eng. 2018, 6, 11904-11912. [CrossRef]

7. Jiang, X.; Li, S.; He, S.; Bai, Y.; Shao, L. Interface manipulation of $\mathrm{CO}_{2}$-philic composite membranes containing designed UiO-66 derivatives towards highly efficient $\mathrm{CO}_{2}$ capture. J. Mater. Chem. 2018, 6, 15064-15073. [CrossRef]

8. Denny, M.S., Jr.; Parent, L.R.; Patterson, J.P.; Meena, S.K.; Pham, H.; Abellan, P.; Ramasse, Q.M.; Paesani, F.; Gianneschi, N.C.; Cohen, S.M. Transmission electron microscopy reveals deposition of metal oxide coatings onto metal-organic frameworks. J. Am. Chem. Soc. 2018, 140, 1348-1357. [CrossRef]

9. Cavka, J.H.; Jakobsen, S.; Olsbye, U.; Guillou, N.; Lamberti, C.; Bordiga, S.; Lillerud, K.P. A new zirconium inorganic building brick forming metal organic frameworks with exceptional stability. J. Am. Chem. Soc. 2008, 130, 13850-13851. [CrossRef]

10. Rodrigues, M.A.; de Souza Ribeiro, J.; de Souza Costa, E.; de Miranda, J.L.; Ferraz, H.C. Nanostructured membranes containing UiO-66 (Zr) and MIL-101 (Cr) for $\mathrm{O}_{2} / \mathrm{N}_{2}$ and $\mathrm{CO}_{2} / \mathrm{N}_{2}$ separation. Sep. Purif. Technol. 2018, 192, 491-500. [CrossRef]

11. Hu, Z.; Khurana, M.; Seah, Y.H.; Zhang, M.; Guo, Z.; Zhao, D. Ionized Zr-MOFs for highly efficient post-combustion $\mathrm{CO}_{2}$ capture. Chem. Eng. Sci. 2015, 124, 61-69. [CrossRef]

12. Huang, H.; Zhang, W.; Yang, F.; Wang, B.; Yang, Q.; Xie, Y.; Zhong, C.; Li, J.-R. Enhancing $\mathrm{CO}_{2}$ adsorption and separation ability of $\mathrm{Zr}$ (IV)-based metal-organic frameworks through ligand functionalization under the guidance of the quantitative structure-property relationship model. Chem. Eng. J. 2016, 289, 247-253. [CrossRef]

13. Hu, J.; Liu, Y.; Liu, J.; Gu, C.; Wu, D. High $\mathrm{CO}_{2}$ adsorption capacities in UiO type MOFs comprising heterocyclic ligand. Microporous Mesoporous Mater. 2018, 256, 25-31. [CrossRef]

14. Abdel-Mageed, A.M.; Rungtaweevoranit, B.; Parlinska-Wojtan, M.; Pei, X.; Yaghi, O.M.; Behm, R.J. Highly active and stable single-atom $\mathrm{Cu}$ catalysts supported by a metal-organic framework. J. Am. Chem. Soc. 2019, 141, 5201-5210. [CrossRef] [PubMed]

15. Qiu, J.; Zhang, X.; Xie, K.; Zhang, X.-F.; Feng, Y.; Jia, M.; Yao, J. Noble metal nanoparticle-functionalized Zr-metal organic frameworks with excellent photocatalytic performance. J. Colloid Interface Sci. 2019, 538, 569-577. [CrossRef]

16. Limvorapitux, R.; Chou, L.-Y.; Young, A.P.; Tsung, C.-K.; Nguyen, S.T. Coupling molecular and nanoparticle catalysts on single metal-organic framework microcrystals for the tandem reaction of $\mathrm{H}_{2} \mathrm{O}_{2}$ generation and selective alkene oxidation. ACS Catal. 2017, 7, 6691-6698. [CrossRef]

17. Bakuru, V.R.; Velaga, B.; Peela, N.R.; Kalidindi, S.B. Hybridization of Pd nanoparticles with UiO-66 (Hf) metal-organic framework and the effect of nanostructure on the catalytic properties. Chem. Eur. J. 2018, 24, 15978-15982. [CrossRef]

18. Mihet, M.; Blanita, G.; Dan, M.; Barbu-Tudoran, L.; Lazar, M.D. Pt/UiO-66 nanocomposites as catalysts for $\mathrm{CO}_{2}$ methanation process. J. Nanosci. Nanotechnol. 2019, 19, 3187-3196. [CrossRef]

19. Li, Z.; Rayder, T.M.; Luo, L.; Byers, J.A.; Tsung, C.K. Aperture-opening encapsulation of a transition metal catalyst in a metal-organic framework for $\mathrm{CO}_{2}$ hydrogenation. J. Am. Chem. Soc. 2018, 140, 8082-8085. [CrossRef]

20. Deng, M.; Bo, X.; Guo, L. Encapsulation of platinum nanoparticles into a series of zirconium-based metal-organic frameworks: Effect of the carrier structures on electrocatalytic performances of composites. J. Electroanal. Chem. 2018, 815, 198-209. [CrossRef]

21. Jiang, D.; Fang, G.; Tong, Y.; Wu, X.; Wang, Y.; Hong, D.; Leng, W.; Liang, Z.; Tu, P.; Liu, L.; et al. Multifunctional Pd@UiO-66 catalysts for continuous catalytic upgrading of ethanol to n-butanol. ACS Catal. 2018, 8, 11973-11978. [CrossRef]

22. Dong, W.; Feng, C.; Zhang, L.; Shang, N.; Gao, S.; Wang, C.; Wang, Z. Pd@UiO-66: An efficient catalyst for Suzuki-Miyaura coupling reaction at mild condition. Catal. Lett. 2016, 146, 117-125. [CrossRef]

23. Luz, I.; Roesler, C.; Epp, K.; Llabres i Xamena, F.X.; Fischer, R.A. Pd@UiO-66-type MOFs prepared by chemical vapor infiltration as shape-selective hydrogenation catalysts. Eur. J. Inorg. Chem. 2015, 3904-3912. [CrossRef]

24. Xiao, J.-D.; Shang, Q.; Xiong, Y.; Zhang, Q.; Luo, Y.; Yu, S.-H.; Jiang, H.-L. Boosting photocatalytic hydrogen production of a metal-organic framework decorated with platinum nanoparticles: The platinum location matters. Angew. Chem. Int. Ed. 2016, 55, 9389-9393. [CrossRef] [PubMed] 
25. Ling, P.; Lei, J.; Jia, L.; Ju, H. Platinum nanoparticles encapsulated metal-organic frameworks for the electrochemical detection of telomerase activity. Chem. Commun. 2016, 52, 1226-1229. [CrossRef] [PubMed]

26. Li, B.; Ma, J.-G.; Cheng, P. Integration of metal nanoparticles into metal-organic frameworks for composite catalysts: Design and synthetic strategy. Small 2019, 1804849. [CrossRef] [PubMed]

27. Jia, X.; Zhang, X.; Rui, N.; Hu, X.; Liu, C.-J. Structural effect of $\mathrm{Ni} / \mathrm{ZrO}_{2}$ catalyst on $\mathrm{CO}_{2}$ methanation with enhanced activity. Appl. Catal. B Environ. 2019, 244, 159-169. [CrossRef]

28. Mei, D.; $\mathrm{Tu}, \mathrm{X}$. Conversion of $\mathrm{CO}_{2}$ in a cylindrical dielectric barrier discharge reactor: Effects of plasma processing parameters and reactor design. J. $\mathrm{CO}_{2}$ Util. 2017, 19, 68-78. [CrossRef]

29. Alliati, M.; Mei, D.; Tu, X. Plasma activation of $\mathrm{CO}_{2}$ in a dielectric barrier discharge: A chemical kinetic model from the microdischarge to the reactor scales. J. $\mathrm{CO}_{2}$ Util. 2018, 27, 308-319. [CrossRef]

30. Sun, K.; Fan, Z.; Ye, J.; Yan, J.; Ge, Q.; Li, Y.; He, W.; Yang, W.; Liu, C.-J. Hydrogenation of $\mathrm{CO}_{2}$ to methanol over $\mathrm{In}_{2} \mathrm{O}_{3}$ catalyst. J. $\mathrm{CO}_{2}$ Util. 2015, 12, 1-6. [CrossRef]

31. Fan, Z.; Sun, K.; Rui, N.; Zhao, B.; Liu, C.-J. Improved activity of $\mathrm{Ni} / \mathrm{MgAl}_{2} \mathrm{O}_{4}$ for $\mathrm{CO}_{2}$ methanation by the plasma decomposition. J. Energy Chem. 2015, 24, 655-659. [CrossRef]

32. Zhou, A.; Chen, D.; Dai, B.; Ma, C.; Li, P.; Yu, F. Direct decomposition of $\mathrm{CO}_{2}$ using self-cooling dielectric barrier discharge plasma. Greenh. Gases Sci. Technol. 2017, 7, 721-730. [CrossRef]

33. Zhou, A.; Chen, D.; Ma, C.; Yu, F.; Dai, B. DBD Plasma- $\mathrm{ZrO}_{2}$ catalytic decomposition of $\mathrm{CO}_{2}$ at low temperatures. Catalysts 2018, 8, 256. [CrossRef]

34. Lee, C.J.; Lee, D.H.; Kim, T. Enhancement of methanation of carbon dioxide using dielectric barrier discharge on a ruthenium catalyst at atmospheric conditions. Catal. Today 2017, 293, 97-104. [CrossRef]

35. Wu, T.B.; Zhang, P.; Ma, J.; Fan, H.L.; Wang, W.T.; Jiang, T.; Han, B.X. Catalytic activity of immobilized Ru nanoparticles in a porous metal-organic framework using supercritical fluid. Chin. J. Catal. 2013, 34, 167-175. [CrossRef]

36. Wu, C.; Irshad, F.; Luo, M.; Zhao, Y.; Ma, X.; Wang, S. Ruthenium complexes immobilized on an azolium based metal organic framework for highly efficient conversion of $\mathrm{CO}_{2}$ into formic acid. ChemCatChem 2019, 11, 1256-1263. [CrossRef]

37. Shang, X.; Deng, D.; Wang, X.; Xuan, W.; Zou, X.; Ding, W.; Lu, X. Enhanced low-temperature activity for $\mathrm{CO}_{2}$ methanation over $\mathrm{Ru}$ doped the $\mathrm{Ni} / \mathrm{Ce}_{\mathrm{x}} \mathrm{Zr}_{(1-\mathrm{x})} \mathrm{O}_{2}$ catalysts prepared by one-pot hydrolysis method. Int. J. Hydrog. Energy 2018, 43, 7179-7189. [CrossRef]

38. Xu, W.; Zhang, X.; Dong, M.; Zhao, J.; Di, L. Plasma-assisted Ru/Zr-MOF catalyst for hydrogenation of $\mathrm{CO}_{2}$ to methane. Plasma Sci. Technol. 2019, 21, 044004. [CrossRef]

39. Wang, L.; Yi, Y.H.; Guo, H.C.; Tu, X. Atmospheric pressure and room temperature synthesis of methanol through plasma-catalytic hydrogenation of $\mathrm{CO}_{2}$. ACS Catal. 2018, 8, 90-100. [CrossRef]

40. Mocniak, K.A.; Kubajewska, I.; Spillane, D.E.M.; Williams, G.R.; Morris, R.E. Incorporation of cisplatin into the metal-organic frameworks UiO66- $\mathrm{NH}_{2}$ and UiO66-encapsulation vs. conjugation. RSC Adv. 2015, 5, 83648-83656. [CrossRef]

41. Pourkhosravani, M.; Dehghanpour, S.; Farzaneh, F. Palladium nanoparticles supported on zirconium metal organic framework as an efficient heterogeneous catalyst for the Suzuki-Miyaura coupling reaction. Catal. Lett. 2016, 146, 499-508. [CrossRef]

42. Xu, G.; Zhang, Y.; Fu, Y.; Guo, Q. Efficient hydrogenation of various renewable oils over Ru-HAP catalyst in water. ACS Catal. 2017, 7, 1158-1169. [CrossRef]

43. Wang, F.; Li, C.; Zhang, X.; Wei, M.; Evans, D.G.; Duan, X. Catalytic behavior of supported Ru nanoparticles on the $\{100\},\{110\}$, and $\{111\}$ facet of $\mathrm{CeO}_{2}$. J. Catal. 2015, 329, 177-186. [CrossRef]

44. Jiang, H.; Gao, Q.; Wang, S.; Chen, Y.; Zhang, M. The synergistic effect of Pd NPs and UiO-66 for enhanced activity of carbon dioxide methanation. J. $\mathrm{CO}_{2}$ Util. 2019, 31, 167-172. [CrossRef]

45. Zhang, S.; Li, L.; Zhao, S.; Sun, Z.; Luo, J. Construction of interpenetrated ruthenium metal-organic frameworks as stable photocatalysts for $\mathrm{CO}_{2}$ reduction. Lnorg. Chem. 2015, 54, 8375-8379. [CrossRef] [PubMed]

(C) 2019 by the authors. Licensee MDPI, Basel, Switzerland. This article is an open access article distributed under the terms and conditions of the Creative Commons Attribution (CC BY) license (http://creativecommons.org/licenses/by/4.0/). 